\title{
CORPO, MOVIMENTO E SUBJETIVIDADES
}

\section{BODY, MOVEMENT AND SUBJECTIVES}

José Roberto da Silva Brêtas ${ }^{1}$, Maila Beatriz Goellner², Daniela Soares Eugênio ${ }^{3}$, Silvia Piedade de Moraes ${ }^{4}$

Submetido em: 08/10/2020

Aprovado em: 14/06/2021

\section{RESUMO}

Estudo qualitativo realizado junto a 30 estudantes do curso de graduação em enfermagem de uma Universidade publica da cidade de São Paulo. Teve por objetivos: identificar as sensações e conhecimentos emergentes das experiências do corpo proporcionadas pela atividade; conhecer o impacto das atividades junto aos estudantes de enfermagem que participaram das oficinas. Por meio da Análise de Conteúdo desvelamos as seguintes categorias: percepção do corpo; subjetividades (conteúdo emocional; autoconhecimento; recordações; consciência do autocuidado); vendo-se; tocar e ser tocado; sobre representações; contribuição pessoal; inter-relacionamento; sugestões e opiniões. Concluiu-se que por meio das atividades vivenciadas, os estudantes puderam ampliar o autoconhecimento por meio de percepções corpóreas. Os resultados obtidos neste estudo contribuíram para o aprimoramento das oficinas.

PALAVRAS-CHAVE: Corpo. Educação. Imagem corporal. Técnicas mente-corpo e de relaxamento.

\section{ABSTRACT}

A qualitative study was carried out with 30 undergraduate nursing students from a public university in the city of São Paulo. It had as objectives: to identify the sensations and emerging knowledge of the experiences of the body provided by the activity; To know the impact of the activities with nursing students who participated in the workshops. Through Content Analysis we uncover the following categories: body perception; Subjectivities (emotional content, self-knowledge, memories, awareness of self-care); Seeing themselves; Touch and be touched; About representations; Personal contribution; Interrelationship; Suggestions and opinions. It was concluded that through the activities experienced, students could increase self-knowledge through corporeal perceptions. The results obtained in this study contributed to the improvement of the workshops.

KEYWORDS: Body. Education. Body Image. Mind-body and relaxation techniques.

\footnotetext{
${ }_{1}^{1}$ Professor Orientador do Programa de Pós-Graduação Educação e Saúde na Infância e Adolescência - Universidade Federal de São Paulo (UNIFESP). jrsbretas@gmail.com

${ }^{2}$ Psicóloga. Doutorado pela UNIFESP. Membro do Instituto Brasileiro de Psicanálise Winnicottiano.

${ }^{3}$ Enfermeira. Mestranda em Ciências pela Universidade Federal de São Paulo (Unifesp). E-mail: daniella.eugenio@gmail.com

${ }^{4}$ Doutora em Ciências: Educação e Saúde na infância e adolescência. Especialista em Educação Sexual, Direito Educacional e Gestão de Ensino. Pedagoga. Docente na Universidade Guarulhos. silviapmoraes@hotmail.com
} 


\section{INTRODUÇÃO}

Estudo realizado junto a uma atividade teórico-vivencial denominada "Oficina do corpo", oferecida como disciplina eletiva a estudantes do curso de graduação em Enfermagem de uma Universidade publica da cidade de São Paulo. Teve como finalidade propiciar experiências sensoriais, autoconhecimento e fornecer subsídios para o cuidado de si e do corpo do outro.

Esta atividade teve como ponto de partida o "cuidado de enfermagem", que em nosso entendimento envolve ação interativa com o cliente, por vezes muito próxima, íntima, de contato físico intenso, que produz um conjunto de sensações e emoções.

Esta ação interativa possibilita comunicação entre profissional e cliente, que vai além do verbal, pois o toque é constante nos procedimentos do cuidado, a expressividade corporal ganha importância singular. Desta forma, o corpo físico, é o instrumento pelo qual essa pessoa pode estabelecer contato, seja consigo próprio, com seu ambiente ou com os demais indivíduos. Neste sentido, Montagu (1988) entende que a comunicação que transmitimos por meio do toque constitui a mais profunda forma de se criar relacionamentos humanos, como fundamento da experiência.

Assim, trabalhar com a consciência da percepção corporal de quem cuida do outro, é ampliar o conhecimento sobre o seu conjunto de expressões, aquilo que é revelado ao cliente. Para viabilizar essa experiência de consciência da percepção corporal, oferecemos oficinas envolvendo um conjunto de atividades, tais como: filmagem da organização corporal durante algumas situações criadas para ocasião; modelagem do corpo em argila; representação gráfica do corpo por meio de desenho; massagem corporal utilizando bolas de tênis; dinâmica envolvendo as técnicas de Eutonia e relaxamento Autógeno.

A Eutonia, por meio de técnicas que envolvem o movimento ajuda o indivíduo a alcançar uma consciência mais profunda de sua realidade corporal e psíquica, como uma verdadeira unidade (ALEXANDER, 1991). Convida o indivíduo a aprofundar na descoberta de si mesmo, amplia sua consciência cotidiana, permite liberação das forças criadoras, um melhor ajustamento a situações de vida e enriquecimento permanente da personalidade e realidade social.

O treinamento autógeno de Schultz (1991) se traduz em exercícios de atitudes expectantes, ritualístico, escalonado, que faz com que fantasias positivas se transformem em realidades positivas. Trata-se de relaxamento e autoindução, a partir de um método psicofisiológico, que segue uma orientação organísmica que escolhe como ponto de partida reações do organismo vivente e não tanto as manifestações psíquicas da consciência, sem omiti-las.

Neste contexto, o objeto de estudo compreendeu percepções de aspectos da corporalidade de estudantes do curso de graduação em Enfermagem que participaram das atividades na "Oficina do corpo", especificamente, como perceberam as sensações emergentes da experiência corporal.

\section{OBJETIVOS}

Teve por objetivos: identificar as percepções emergentes das experiências corporais; conhecer o impacto das atividades desenvolvidas junto aos estudantes que participaram da oficina do corpo.

\section{MÉTODO}

Trata-se de um estudo de orientação qualitativa, com o uso do método Análise de Conteúdo, especificamente a análise categorial, que traduziu uma forma de categorização de dados verbais e/ou comportamentais, sendo o objeto da análise a mensagem contida nas comunicações orais ou escrita (BARDIN, 2011).

O projeto deste estudo foi avaliado e aprovado pelo comitê de Ética da UNIFESP com parecer $n^{\circ} 2.222 .639$, CAAE: 72273117.5.0000.5505, obedecendo todos os padrões estabelecidos pela resolução 466/12, que trata das normas de pesquisa envolvendo seres humanos (BRASIL, 2013). Ressaltamos que o termo de assentimento foi 
CORPO, MOVIMENTO E SUBJETIVIDADES José Roberto da Silva Brêtas, Maila Beatriz Goellner, Daniela Soares Eugênio, Silvia Piedade de Moraes

devidamente esclarecido e assinado pelos participantes do estudo.

Os participantes do estudo foram 30 jovens na faixa etária entre 18 e 24 anos de idade, matriculados em um curso de graduação em Enfermagem de uma universidade pública da cidade de São Paulo. O Estatuto da Juventude (2013) considera jovem o indivíduo entre 14 e 29 anos de idade, trata do período de interstício entre as funções sociais da infância e as funções sociais do ser adulto. Trata-se de uma categoria social, que é uma concepção, representação ou criação simbólica, criada por grupos sociais, para significar uma série de comportamentos e atitudes a ela atribuídos (GROPPO, 2000).

Como princípio de inclusão adotou-se as seguintes premissas: aceitar espontaneamente participar do estudo; estar inscrito e participando da oficina.

O campo de estudo constituiu-se de uma atividade denominada "Oficina do corpo", de caráter teórico-vivencial, realizada com dois grupos de participantes.

Como instrumento para coleta de dados optou-se pela entrevista individual e sua viabilização deu-se por meio de três perguntas norteadoras: Como percebeu sua participação nas atividades realizadas durante a oficina? Qual foi a contribuição pessoal da oficina? Qual a avaliação que você faz da oficina?

A análise dos dados foi realizada pela leitura integral das narrativas de cada participante tentando compreender as suas experiências. Foram lidos de tal forma a obter-se um sentido geral do todo de cada relato. Em seguida, realizamos uma releitura de cada relato buscando o significado que teve o sujeito acerca da temática. Assim, promovemos a estruturação em categorias, buscando contornos do sistema de significação que, no seu conjunto revelaram o impacto da experiência sobre os estudantes entrevistados (BARDIN, 2011).

\section{RESULTADOS}

Com a estruturação em categorias, buscamos os contornos do sistema de significação que, no seu conjunto revelaram a percepção dos participantes entrevistados sobre a experiência vivenciada nas "oficinas do corpo", organizadas e apresentadas no quadro que segue.

Quadro1- Categorização e apresentação das experiências dos participantes da Oficina do corpo.

\begin{tabular}{|ll|}
\hline Categorias & Unidades significativas \\
\hline $\begin{array}{l}\text { Percepção do } \\
\text { corpo }\end{array}$ & $\begin{array}{l}\text { Por meio dos exercícios propostos pude perceber a contração dos músculos } \\
\text { da perna e coxa, pois, normalmente não percebemos a contração, pelo menos } \\
\text { eu nunca tinha percebido aqueles músculos. Então, quando o professor } \\
\text { falava: "contrai o músculo do antebraço, eu ficava pensando como se contrai } \\
\text { esses músculos?". Nós fazemos tanto no automático, que quando pediu para } \\
\text { contrair fiquei pensando como contrair o braço e antebraço sem dobrar? (P2, } \\
\text { sexo feminino). } \\
\text { Com as atividades realizadas pude perceber os movimentos, a forma como o } \\
\text { corpo realiza as funções, sentir o corpo como fossem os movimentos (P1, } \\
\text { P10, sexo feminino). } \\
\text { Nunca tinha parado para refletir sobre o meu corpo, cada parte dele, } \\
\text { pensando em cada pedacinho, cada fragmento meu. Foi uma experiência } \\
\text { nova, diferente para mim (P17, sexo feminino). }\end{array}$ \\
\hline
\end{tabular}




\begin{tabular}{|c|c|}
\hline Subjetividades & $\begin{array}{l}\text { Conteúdo emocional } \\
\text { Em alguns momentos sensações desagradáveis e desconfortáveis, em outros } \\
\text { momentos tinha uma sensação muito boa, prazerosa, uma sensação de que } \\
\text { você é único. ( } \mathrm{P} 3 \text {, sexo feminino). } \\
\text { Cada atividade teve uma sensação e eu não irei me lembrar de todas as } \\
\text { atividades. Em algumas me senti ansiosa, outras eu fiquei cansada, outras } \\
\text { fiquei feliz. Em cada atividade tive uma sensação diferente porque me fez } \\
\text { sentir um pouco, como eu me comporto em determinadas situações (P11, } \\
\text { sexo feminino). } \\
\text { Autoconhecimento } \\
\text { Por meio das atividades pude me observar melhor e perceber como estava me } \\
\text { sentindo e o quê o meu corpo estava precisando ( } \mathrm{P8} \text {, sexo feminino). } \\
\text { Recordações } \\
\text { Recordei-me de uma história da minha infância em que estava no velório do } \\
\text { padre da minha escola e quase desmaiei, só para não desobedecer a uma } \\
\text { ordem. E no momento dessa atividade na eletiva me percebi obediente } \\
\text { demais (P13, sexo feminino). } \\
\text { Consciência do autocuidado } \\
\text { Quando entramos na enfermagem parece que é introjetado "o outro"; nós } \\
\text { somos preparados para cuidar do outro, mas que base tem para cuidar do } \\
\text { outro se não nos conhecemos, não sabemos como funcionamos. Será que se } \\
\text { cuidássemos melhor de nós, não cuidaríamos melhor do outro? (P2, P11, } \\
\text { sexo feminino). }\end{array}$ \\
\hline Autoimagem & $\begin{array}{l}\text { A filmagem foi muito chata, não gostei de me ver. Toda semana que } \\
\text { assistimos sentia uma coisa esquisita, não queria olhar, queria olhar para o } \\
\text { outro lado, mas sei que ficaria chato não olhar, por isso, acabava olhando. } \\
\text { Não gostei do jeito que eu falava, não gostei de como caminhava, não gostei } \\
\text { de nada do que assisti, e essa sensação não mudou durante todas às vezes } \\
\text { que assisti as cenas ( } \mathrm{P} 15 \text {, sexo feminino). } \\
\text { Foi horrível, porque eu ouvi que minha voz e pude ver a expressão corporal, } \\
\text { que são diferentes do que imaginava, é estranho saber que os outros me } \\
\text { veem de uma forma a que eu não imagino. Pensei que eu era diferente ( } \mathrm{P} 4 \text {, } \\
\text { sexo feminino). } \\
\text { Na hora que você se está se enxergando como se fosse outra pessoa, é } \\
\text { possível ver como reage diante das situações. Foi bem surpreendente ( } \mathrm{P3} \text {, } \\
\text { sexo feminino). } \\
\text { Ver-me falando foi horrivel, não gostei muito, não sei falar, não gosto de falar } \\
\text { em público, mas eu sei que isso é importante. Através da filmagem vi os meus } \\
\text { gestos e que a toda hora eu não queria me expor. ( } \mathrm{Pg} \text {, sexo feminino). }\end{array}$ \\
\hline $\begin{array}{l}\text { Relacionamento e } \\
\text { comunicação }\end{array}$ & $\begin{array}{l}\text { O exercício com a bolinha foi um diálogo corporal com o outro. Na atividade } \\
\text { você tem que se fazer entender sem nenhuma palavra. Parei para ouvir mais } \\
\text { o quê o outro tinha a me dizer, tive oportunidade de conhecer melhor as } \\
\text { pessoas e perceber que cada indivíduo é diferente, age diferente, e conhecer } \\
\text { melhor a atitude das pessoas ( } \mathrm{P} 10 \text {, sexo feminino). } \\
\text { Cada dia de atividade foi diferente, foi possível descobrir um pouco mais as } \\
\text { pessoas do grupo, o que sentem e o que elas são. As atividades propostas } \\
\text { ajudaram a desenvolver uma interação, possibilitou a percepção de fazer parte } \\
\text { de um grupo ou de um conjunto ( } \mathrm{P} 8 \text {, sexo feminino). } \\
\text { Acabei percebendo como é o jeito do outro, vendo como o outro é realmente, } \\
\text { na oficina havia pessoas que eu não conhecia, porque os participantes veem } \\
\text { de séries diferentes, mas durante a eletiva formamos um grupo gostoso. } \\
\text { Depois das oficinas mantivemos contato e as pessoas passaram a se falar e } \\
\text { cumprimentar ( } \mathrm{P} 21 \text {, sexo feminino). }\end{array}$ \\
\hline
\end{tabular}




\begin{tabular}{|c|c|}
\hline $\begin{array}{l}\text { Tocar e ser } \\
\text { tocado }\end{array}$ & $\begin{array}{l}\text { Na hora que eu estava recebendo a massagem foi muito gostoso, porque me } \\
\text { fazia relaxar. Na hora de fazer no outro era estranho, por estar tocando no } \\
\text { corpo do outro, mesmo sendo de maneira indireta, com a bolinha, mas de uma } \\
\text { forma ou de outra, você estava mexendo no corpo do outro. Há partes que } \\
\text { você fica meio constrangido e toca mais rápido. Na maioria das vezes eu fiz } \\
\text { parceria com uma pessoa conhecida, mas quando estive com quem eu não } \\
\text { conhecia, tinha restrição para fazer a massagem porque é estranho mexer no } \\
\text { corpo do outro (P16, sexo feminino). } \\
\text { Muito bom, no começo estávamos receosos, porque iríamos fazer massagem } \\
\text { em uma pessoa desconhecida. Tem a questão do toque, de você estar lá } \\
\text { deitado e fazer o que quiser; então você fica meio receoso no começo, mas } \\
\text { depois com o passar dos dias nós chegávamos na atividade pedindo } \\
\text { massagem (P3, sexo feminino). } \\
\text { É estranho, mas tive a consciência de que o outro tem um corpo e que ele } \\
\text { sente quando é tocado, da mesma forma que me senti quando fui tocada. } \\
\text { Melhorou a minha percepção do toque. Talvez tenha barreiras, não é fácil um } \\
\text { procedimento tão íntimo (P16, sexo feminino). } \\
\text { Alguém fazendo a massagem em você, uma pessoa usando uma bolinha para } \\
\text { fazer alguma coisa em você e depois você retribuindo para essa pessoa, foi } \\
\text { algo que me ajudou no envolvimento maior com o ambiente, sair do meu } \\
\text { conforto e ter mais contato e exposição (P17, sexo feminino). }\end{array}$ \\
\hline $\begin{array}{l}\text { Representações } \\
\text { do corpo }\end{array}$ & $\begin{array}{l}\text { A representação depende da minha vida, da minha cultura, do social, a forma } \\
\text { como me represento, as minhas atitudes dependem dos meus valores, do que } \\
\text { eu vivo, de como eu estou, das circunstâncias ( } \mathrm{P} 2 \text {, sexo feminino). } \\
\text { Quando nós desenhamos uma determinada figura, significa que nós } \\
\text { estávamos também tentando expressar nossos sentimentos e emoções. Eu } \\
\text { acho que podemos perceber isso nos desenhos das pessoas ( } \mathrm{P} 4 \text {, sexo } \\
\text { feminino). } \\
\text { Graficamente você percebe o corpo de um jeito, usando massa modelar } \\
\text { percebe o corpo de uma forma tridimensional ( } \mathrm{P} 1 \text {, sexo feminino). }\end{array}$ \\
\hline $\begin{array}{l}\text { Contribuição } \\
\text { pessoal }\end{array}$ & $\begin{array}{l}\text { Ajudou muito na questão de parar para descansar, não fazer nada, ajudou a } \\
\text { ficar mais calma, menos tensa e preocupada ( } \mathrm{P} 3 \text {, sexo feminino). } \\
\text { Mudou muito a minha percepção, ajudou bastante o meu crescimento como } \\
\text { pessoa e como profissional, também me ajudou a lidar com o outro ( } \mathrm{P} 23 \text {, sexo } \\
\text { feminino). } \\
\text { Essa disciplina eletiva foi um aprendizado que eu levo para minha vida toda } \\
\text { (P14, sexo masculino). }\end{array}$ \\
\hline $\begin{array}{l}\text { Sugestốes e } \\
\text { opiniốes }\end{array}$ & $\begin{array}{l}\text { Julgo que esta disciplina eletiva foi boa e interessante. Deveria ser aberta, não } \\
\text { deveria ser uma eletiva. Deveria ter um curso que fosse extracurricular, } \\
\text { optativo, mais vezes durante o ano (P10, sexo feminino). } \\
\text { Foi uma disciplina diferente, eu não esperava. Foi boa e eu achei muito } \\
\text { interessante. É diferente, na universidade o mais comum é estudar, ter aulas } \\
\text { expositivas, fazer trabalhos, mas uma disciplina para você perceber o seu } \\
\text { corpo, achei bem interessante ( } \mathrm{P} 7 \text {, feminino). } \\
\text { Acho que se pudéssemos escolher o grupo e fazer a disciplina eletiva apenas } \\
\text { com nossos amigos, acredito que poderia ser melhor. (P19, sexo feminino). } \\
\text { Como a disciplina superou as minhas expectativas no bom sentido, considero- } \\
\text { a muito boa, porque seguindo os objetivos que foram apresentados no } \\
\text { primeiro dia ela era para o aluno (P12, sexo feminino). } \\
\text { Deveria tentar colocar a oficina na grade curricular do curso de graduação em } \\
\text { Enfermagem ( }(\mathrm{P} 22 \text {, sexo feminino). }\end{array}$ \\
\hline
\end{tabular}




\begin{abstract}
Eu acho que foi boa. Achei bem interessante para a formação do estudante de enfermagem, porque proporciona um momento de reflexão sobre o corpo, que às vezes nos esquecemos. Achei interessante, acho que mais pessoas poderiam participar desde que fosse de livre escolha, porque se tornar uma atividade obrigatória poderia perder sua função ( $\mathrm{P} 14$, sexo masculino).
\end{abstract}

\title{
DISCUSSÃO
}

A categoria "percepção do corpo" foi definida pela aquisição de conhecimento do corpo por meio dos sentidos. Podemos afirmar que são cinco sentidos fundamentais: visão, audição, olfato, paladar e tato, estes recebem estímulos externos e os transmitem ao cérebro, por meio de nervos sensoriais, provocando sensações, que consistem na impressão física geral. Portanto, podemos dizer que a percepção é proveniente da sensação, como esta exemplificada no quadro 1.

Esta categoria demonstrou que a estimulação e sensibilização da pele proporcionaram aos participantes percepções e consciência de seus corpos, por meio de reflexão e atenção focada em diferentes partes do corpo. Nesse contexto, a mobilização do tônus muscular e a atenção focada em determinadas partes do corpo, possibilitou a consciência de volume, espaço interior, pele, tecidos, órgãos e esqueleto.

Vale ressaltar que a proposta da Eutonia foi explorar, tomar consciência, aguçando e concentrando a atenção nas sensações obtidas nas diferentes partes do corpo.

Nesse sentido, Schultz (1991) refere que o homem ensimesmado se aliena do exterior e introverte-se; muitas impressões externas Ihe escapam totalmente ou, pelo menos, encontra nele uma ressonância muito fraca devido à indiferença às coisas exteriores. As vivências próprias e internas são as mais ricas, possuem mais forma e colorido e isso faz surgir uma alteração peculiar. Assim, Bertazzo (2010) refere que é a partir da consciência interna do movimento que poderemos então conceitualizar o espaço externo e estabelecer relação com ele e com os objetos e seres que nos rodeiam.

Observou-se por meio das narrativas que os participantes apresentaram dificuldades na realização dos processos fisiológicos como contração e relaxamento. A dificuldade em realizar tais processos está relacionada ao fato de que normalmente no cotidiano o individuo não percebe seus gestos, a menos que tenha treinamento para isso (BERTAZZO, 2010).

Submetidos aos referidos processos, os participantes perceberam diferenças em seus corpos, antes e depois das atividades propostas, suscitando as sensações mencionadas anteriormente.

A categoria "subjetividades" consistiu na descoberta de algo relativo ao sujeito, tendo o caráter individual, pessoal e particular. De acordo com o significado desta categoria emergiram três subcategorias que foram: conteúdo emocional, autoconhecimento e recordações.

Podemos entender subjetividade como a organização dos processos de sentido e se organizam de diferentes formas e em diferentes níveis no sujeito e na personalidade, assim como nos diferentes espaços sociais em que 0 sujeito atua (GONZÁLEZ REY, 2003).

O conteúdo emocional consistiu em uma reação intensa e inesperada do organismo, a qual foi acompanhada por um estado afetivo de conotação penosa ou agradável. Nas oficinas, os participantes foram submetidos a atividades voltadas à expressão pessoal e sensibilização de diferentes partes do corpo, como por exemplo, relaxamento e sensibilização da região plantar dos pés por meio de massagem com uma bola de tênis.

Por meio de movimentos, de postura, dos gestos, da percepção, do contato com a bola de tênis, emergiram sensações prazerosas e desconfortáveis, manifestadas por sensações e comportamentos como: tranquilidade, alegria, ansiedade e prazer. Assim puderam perceber como se comportaram nas diferentes situações que foram atores.

As sensações emergentes foram justificadas pelo fato de que o movimento pode provocar alegria, raiva, vontade de chorar, entre outras manifestações. Isso é natural, o gesto afeta, pois faz com que os indivíduos entrem em contato com a emotividade e com as pulsações básicas (BERTAZZO, 2010). 
A subcategoria "autoconhecimento" teve origem no conjunto de atividades que propiciou emersão de elementos pessoais, possibilitando a expansão da consciência de atos, gestos e sobre questões referentes à sua própria subjetividade.

Das atividades propostas nas oficinas emergiram elementos pessoais, possibilitando aos participantes o exercício do autoconhecimento. A experiência propiciou o contanto mais profundo consigo e a possibilidade de reflexões acerca de si mesmo.

O termo recordação diz respeito a recordar, que consiste em lembrar, fazer vir à memória, porém a lembrança realiza-se por meio de analogia ou semelhança. Nesse sentido, as lembranças são suscitadas pelas sensações, por meio do gesto, do movimento e estimulação dos sentidos.

Esta subcategoria demonstrou que certas atividades proporcionaram lembranças do passado, emergidas da memória corporal de vivências anteriores. Nesse sentido, convém explicar que a memória é a faculdade de se representar o passado, o que nele foi aprendido, vivido, corporificado e, principalmente, o que foi sentido e tudo o que se vincula aos traços dos tempos passados. Todas as situações vividas se inscrevem no inconsciente, com todas as suas referências, para, no momento oportuno, reaparecer na consciência (KELEMAN, 1996).

Vale ressaltar que a memória é a base da identidade, isto é, a possibilidade de se reconhecer a si e por si. Ninguém esquece o que foi, nem o que é ou acredita ser. Assim, a memória fundamenta a representação que cada um faz de si; aquilo que evocamos quando digo "Eu", é aquilo em que cada um se encontra a si mesmo, por si. Portanto, a identidade se inscreve na memória, ela está marcada no corpo, aparecendo quando evocada pelo gesto, na postura e na mímica que modelam o corpo e o rosto, fazendo de cada um, um ser singular.

Neste sentido, sabemos que cada indivíduo tem seu modo de andar ou de correr, até de ficar parado, de sorrir, ou de usar o talher. O determinismo desses movimentos, em sua forma, é inconsciente, ou seja, pertence à memória do corpo.

Isso quer dizer que existe uma memória corporal e certamente, é um elo profundo que liga a vida psíquica aos sons, aos movimentos, às posturas, às reações motoras, impressos no corpo (BRÊTAS et al., 2006).

Independentemente do tempo, o corpo sente, reconhece, revive a alegria, o terror, o desespero e a angústia, evocados por um som, um toque, e retoma, revive a postura, por sua vez evocada, com toda a sua intensidade. Estabelece relações entre as emoções e as sensações cinestésicas, fazendo com que o corpo reviva a intensidade de um momento já esquecido, fazendo aflorar no corpo, uma memória tônica e psicomotora, na forma de sensações de ansiedade, de calma, de prazer, dor, medo e muitas outras manifestações.

Tudo isso se deve ao fato de que o ser humano vive as ações cotidianas, os movimentos e as posturas, gravando e memorizando cada movimento e ação, dia após dia, de hora em hora, o corpo escreve a sua história, em toda sua intensidade tônica e emotiva.

Neste contexto, pode-se dizer que no decorrer da vida, o corpo armazena sensações e vivências afetivas, positivas ou negativas. Algumas destas sensações se depositaram nas lembranças como sedimentos, deixando uma impressão gravada no subconsciente. Essa memória rege as ações e reações, toda vez que a memória corporal desperta diante dos outros (BRÊTAS et al., 2006).

A consciência do autocuidado consiste em conhecimento, noção, idéia da diligência, desvelo e zelo. Quando se fala de autocuidado pensa-se em atividades que vão desde rotinas diárias como: vestir-se, calçar sapatos, tomar banho, alimentar-se até questões mais complexas, como cuidar da própria saúde física e mental.

Nessa subcategoria emergiram questões referentes à necessidade e valorização do autocuidado, principalmente em profissionais da área da saúde. Por meio dos relatos observou-se a associação do autocuidado com o benefício próprio e a melhora da qualidade do cuidado ao paciente.

Cuidar implica uma atenção ao self, o cuidador antes de cuidar dos outros, necessita estar atento ao seu olhar interior, cuidando de si antes de cuidar dos outros. Desta forma, entendemos que se o cuidador for capaz de cuidar de si, terá melhores condições de vida e melhores condições de cuidar do outro (VIEIRA, ALVES, KAMADA, 2007).

Neste sentido, Foucault (2014) afirma que quem cuida de modo adequado de si mesmo, encontra-se em condições de relacionar-se e de conduzir-se adequadamente na relação com os demais. 
Referindo-se a cultura de si, ou seja, a um período histórico onde foram intensificadas e destacadas as relações de si para consigo, Foucault observa que é em Epicteto que se desenrola a mais alta elaboração sobre o cuidado de si. Segundo o filósofo helenista, os homens necessitam apreender este cuidado de si porque não vieram prontos, deus o dotou apenas de razão. "É na medida em que é livre e racional - e livre de ser racional - que o homem é na natureza o ser que foi encarregado do cuidado de si próprio"( FOUCAULT, 2014, p.53).

Mesmo com suas particularidades, Foucault (2014) formaliza que o objetivo comum dessas práticas de si é a conversão a si, quer dizer, "manter em mente que o fim principal a ser proposto para si próprio deve ser buscado no próprio sujeito , na relação de si para consigo"(p.69).

À medida que se cria um conhecimento de si, cria-se um sujeito de um ethos preciso. Assim as práticas de si serviam aos homens livres e tinham em sua ontologia a autonomia necessária para se recriar a autotransformação no espaço do indivíduo. Busca-se adquirir aptidões, assim como atitudes (FOUCAULT, 2010).

Se pensarmos que o cuidado de si implica um cuidado do outro, isso implica em uma ética, e sendo ético, se é, portanto, para com o outro. Nesse sentido, Foucault (2010) explica que para os gregos, o cuidado de si é ético em si mesmo.

Para Foucault (2010) o ethos implica uma relação com os outros na medida em que o cuidado de si é capaz de ocupar, na cidade, na comunidade ou nas relações interindividuais, o lugar adequado.

Descobrir é uma forma de notar ou perceber algo ocultado parcial ou totalmente. Na categoria descoberta da autoimagem emergiu das narrativas desveladas por meio da filmagem de uma situação planejada, em que nas apresentações os indivíduos tiveram como pauta falar sobre si.

Nesta categoria observou-se que a maioria dos sujeitos se sentiu incomodado ao serem expectadores de sua própria imagem, sendo este motivo de surpresa, incomodo, constrangimento e raiva. Neste sentindo, Keleman (1994) afirma que a maioria das pessoas está acostumada a se reconhecer apenas por uma imagem ou papel estático.

Os estados sentimentais foram provenientes do conflito entre imagem real e idealizada. Por meio dos relatos pode-se identificar a imagem real como sendo aquela que os graduandos viram na filmagem e se decepcionaram, enquanto que a imagem idealizada é aquela que eles julgavam que transmitiam ao outro, essa diferença fez com que alguns deles se questionassem sobre o que viram.

Nesse sentido, Keleman $(1994,1992)$ refere que desde cedo os indivíduos criam padrões de ação que condizem com a imagem que pensam ter ou deveriam ser e então se identificam com o padrão de ação que criam. Assim, os mesmos pensam que têm um corpo que lhes obedece.

Alguns participantes associaram determinados gestos presentes no momento de sua filmagem a como se sentiam no momento da gravação. Neste sentido, o gesto que é contingente em relação à organização corporal, é a própria maneira de acolher a situação e vive-la, principalmente quando se trata da expressão de emoções (PONTY, 2010).

A filmagem teve por finalidade mostrar como os sujeitos se organizaram em determinadas situações, permitindo que tomassem conhecimento de como se organizam fisicamente a sua estrutura somática para sustentar a emoção do momento. No presente contexto Keleman (1994) refere que o exercício do "como" ensina a reconhecer as sensações de auto-organização, as fases da prontidão para agir, as imagens e os padrões que emergem.

O prestar atenção permitiu que as experiências fossem sentidas por si mesmas. Pois a percepção do processo não faz de nós observadores, mas, antes, auto expectadores, empáticos com nós mesmos, unindo o cognitivo, o emocional e o físico e assim, nos ensina a ligação e a totalidade (KELEMAN, 1994).

A categoria "relacionamento e comunicação" consistiu na capacidade de maior ou menor grau em se relacionar e se comunicar com o outro. A situação envolvendo o inter-relacionamento foi criada por meio de algumas atividades que envolviam a interação coletiva como: estimulação sensorial de partes do corpo com bola de tênis, comunicação não verbal e compartilhamento das experiências emergentes a cada oficina.

Os relatos demonstram que os participantes estavam suscetíveis ao conhecimento do outro e as suas necessidades, além do conhecimento a cerca da forma de como ocorreu a relação. Possibilitou também aos participantes 
de uma forma geral, o compartilhamento das suas emoções com o grupo a cada final de oficina e assim puderam exercitar o conhecimento de si e dos outros. Como consequência obteve-se a melhora no relacionamento interpessoal deles, desta forma, a atividade pode ser considerada um espaço propiciador da formação de vínculo.

$O$ ato de tocar e ser tocado consiste em contato com o outro, sendo sempre apontado como um tipo especial de proximidade, pois quando uma pessoa toca a outra, a experiência inevitavelmente é recíproca (KELEMAN, 1992). Tanto o tocar como ser tocado é mediado pelo toque. Assim, o toque é considerado uma das maneiras mais importantes de comunicação não verbal, podendo enviar mensagens positivas ou negativas para o quem recebe. Tem como finalidade ser um meio de comunicação e interação (MONTAGU, 1988).

Para alguns participantes o toque teve a função de: aumentar o contato com ambiente levando a um maior envolvimento, interação, estímulo para consciência do corpo do outro. Nesse contexto, quando sentimos os objetos concretamente, além dos limites do corpo, também experimentamos ao mesmo tempo o próprio eu. Sinto simultaneamente o objeto e eu mesmo (MONTAGU, 1988).

Tanto o tato como o contato provocaram diferentes sensações daquelas vividas no cotidiano. Assim, embora o tato não seja em si uma emoção, seus elementos sensoriais induzem alterações neuronais, glandulares, musculares e mentais, que, combinadas, denominamos emoção. Disto decorre que o tato não é sentido como uma simples modalidade física, como a sensação, mas também, efetivamente como uma emoção (MONTAGU, 1988).

Outros participantes referiram que a sensibilização do corpo com a bola de tênis proporcionou desconforto e constrangimento, pelo fato de tocar o outro, tais sentimentos diminuíram e cessaram com o passar das oficinas. Observou-se que antes das atividades havia receio de tocar o corpo do outro, o que é intrigante na profissão enfermeiro, pois na maior parte do tempo este profissional cuidará e atuará junto ao corpo do cliente.

A categoria "representações do corpo" consistiu no ato ou efeito de representar e reproduzir aquilo que se pensa, por meio do conteúdo concreto captado pelos sentidos e gravado na memória.

O conteúdo dessa categoria desvelou a representação da experiência do corpo por meio de desenhos em espaço gráfico e em massa de modelar.

Nesta categoria observou-se que as representações gráficas expressaram os sentimentos, emoções das situações que estavam vivenciando, envolvendo valores socioculturais e características pessoais dos participantes.

Os conteúdos contidos nas narrativas referiram-se às condições e aos contextos nos quais emergiram as representações e as formas de comunicação que serviram na interação com o outro. Toda representação é de alguém e sobre alguma coisa, definindo-se por um lado por meio de seu conteúdo (informações, imagens, opiniões, atitudes) em relação a um objeto ou um sujeito (indivíduo, grupo). A representação não é a duplicação do real, nem duplicação da idéia, nem a parte subjetiva do objeto, nem a parte objetiva do sujeito. No fundo de toda a representação devemos buscar esta relação com o mundo e com as coisas (BRÊTAS et al., 2009).

Como descrito anteriormente observou-se conteúdo emocional e sentimental nos relatos dos entrevistados, tais aparições estão relacionados ao caráter simbólico e imaginativo dos saberes sociais, estes trazem à tona a dimensão dos afetos, quando os sujeitos sociais se empenham em entender e atribuir sentido ao mundo (BRÊTAS et al., 2009).

A análise de conteúdo ainda nos possibilitou desvelar a categoria "contribuição pessoal", a qual tem por significância o ato ou efeito de contribuir. Mostra que a participação nas atividades da oficina proporcionou aos sujeitos mais que o tomar consciência das percepções corporais, algo de significante, experiência pessoal que denotou o conhecimento de algo agregado a si mesmo.

Durante o período das oficinas as atividades contribuíram para que os participantes pudessem relaxar e descansar, esquecer os problemas que estavam vivenciados, tranquilizar-se, refletir sobre questões e cuidados referentes ao corpo. $\mathrm{E}$ ao término das oficinas alguns dos graduandos conseguiram utilizar os recursos vivenciados nas atividades para lidar com seus estados emocionais.

A categoria "opiniões e sugestões" apresentou dois conceitos, o primeiro referiu-se ao modo de ver, de pensar uma determinada situação vivida. Enquanto o segundo consistiu em ato ou efeito de se sugerir, este por sua vez denota fazer que se apresentasse uma noção por menção ou associação de idéias. 
De uma forma geral, todos os participantes gostaram da disciplina eletiva e avaliaram-na como importante e fundamental. As atividades da oficina foram encaradas pelos participantes como um aprendizado prático que fugiu dos padrões convencionais propostos pela universidade, tanto no que se refere ao tema quanto à forma na qual foi oferecida. Por meio dos relatos observou-se que os graduandos sentem a falta de atividades que promovam a reflexão de questões referentes a si e que na maioria das vezes o foco das atividades propostas pelo curso referiu-se ao "outro". Em relação ao método, entendeu-se a vivência como forma de aprendizado.

É importante lembrar que quando é solicitado avaliação de qualquer atividade, têm-se opiniões diferentes, embora todos os sujeitos tenham participado das mesmas atividades, a vivência de cada um foi única.

Quanto ao que refere à permanência das oficinas como atividade fixa do curso de graduação as opiniões se dividem em dois grupos, os que sugeriram que esse tipo de atividade não seja obrigatório, devendo participar apenas aqueles que estão de acordo com a proposta, enquanto outros sugeriram que as atividades deveriam ser realizadas com pessoas mais próximas da convivência do dia a dia.

As sugestões que formaram esta categoria foram elementos muito importantes para avaliação das atividades proporcionadas pela "Oficina do corpo", podendo reforçar alguns aspectos e proporcionar a reformulação para uma próxima atividade.

\section{CONSIDERAÇÕES FINAIS}

O conjunto de atividades oferecidas na Oficina do corpo possibilitou aos participantes, autoconhecimento, a partir da consciência das suas sensações. A oficina possibilitou um campo de experiências agradáveis e de forte impacto aos participantes, propiciadora de reflexões referentes ao próprio corpo e ao corpo do outro, que pode ou não ser sujeito de cuidados.

Os resultados do estudo demonstraram a relevância das experiências fornecidas pela oficina na formação do graduando de enfermagem, trabalhar com o corpo de quem cuida do corpo do outro é ampliar a ferramenta de cuidado, e possibilitar que o futuro profissional cuide melhor de si e do outro. Desta forma, podemos afirmar que a "Oficina do corpo" está no caminho certo, e que suas atividades provavelmente repercutirão no cuidado prestado ao paciente.

Assim, os dados obtidos neste estudo superaram nossas expectativas e certamente contribuirão para o aprimoramento das atividades oferecidas em forma de oficina.

\section{REFERÊNCIAS}

ALEXANDER Gerda. Eutonia: um caminho para percepção corporal. São Paulo: Martins Fontes, 1991.

BARDIN Laurence. Análise de Conteúdo. Lisboa - Portugal: Edições 70, 2011.

BERTAZZO Ivaldo. Cidadão Corpo: Identidade e Autonomia do Movimento. São Paulo: Editora Summus, 2010.

BRASIL. Conselho Nacional de Saúde Resolução 466/12. Brasília: Diário Oficial da União, n. 12, Seção 1 - pg. 59, 2013.

BRASIL. Estatuto da Juventude: atos internacionais e normas correlatas - Lei 12.852/2013. Brasília: Senado Federal, Coordenação de Edições Técnicas, 2013.

BRÊTAS, J. R. S.; LIMA, Renata Campos; YAMAGUTI, Lie. O Corpo que cuidamos. In: BRÊTAS Ana Cristina Passarella; GAMBA Mônica Antar (Org.). Enfermagem e saúde do adulto. São Paulo: Manole, 2006. 
BRÊTAS, J. R. S.; MUROYA, Renata L.; GOELLNER, Maila Beatriz. Mudanças Corporais na Adolescência. In: BORGES, A. L. V.; FUJIMORI, E. (Org.) Enfermagem e a saúde do adolescente na atenção básica. Barueri (SP): Manole, 2009.

FOUCAULT, Michel. História da Sexualidade: O cuidado de si. São Paulo: Editora Paz e Terra, 2014. vol. 3.

FOUCAULT Michel. Hermenêutica do sujeito. São Paulo: Martins Fontes, 2010.

GONZÁLEZ REY, F. Sujeito e subjetividade: uma aproximação histórico-cultural. São Paulo: Thomson Pioneira, 2003.

GROPPO, Luís Antônio. Juventude: ensaios sobre sociologia e história das juventudes modernas. Rio de Janeiro: DIFEL, 2000.

KELEMAN, Stanley. Anatomia emocional: a estrutura da experiência. São Paulo: Summus Editorial, 1992.

KELEMAN, Stanley. Realidade somática: experiência corporal e verdade emocional. São Paulo: Summus Editorial, 1994.

KELEMAN, Stanley. O corpo diz sua mente. São Paulo: Summus Editorial, 1996.

PONTY, Merleau. Fenomenologia da percepção. São Paulo: Martins Fontes, 2006.

MONTAGU, Ashley. Tocar: significado humano da pele. 9. ed. São Paulo: Summus editorial, 1988.

SCHULTZ, JH. O treinamento autógeno. São Paulo: Editora Manole, 1991.

VIEIRA, A. B. D.; ALVES, E. D.; KAMADA, I. Cuidando do cuidador: percepções e concepções de auxiliares de enfermagem acerca do cuidado de si. Texto \& Contexto Enferm, v. 16, n. 1, p.15-25, 2017. 